DOI: 10.12957/demetra.2016.16083

\title{
Comer, nadar, caminhar e brincar: o piquenique do Ginásio Santa Catarina (1906-1918)
}

\section{Eat, swim, walk and play: the picnic of Ginásio Santa Catarina (1906-1918)}

Thiago Perez Jorge ${ }^{1}$

\author{
1 Universidade Federal de Santa Catarina, \\ Programa de Pós-graduação em História. \\ Florianópolis-SC, Brasil.
}

Este ensaio é um dos produtos da tese do autor, na área de História Cultural junto ao Programa de Pós-graduação em História (PPGH), da Universidade Federal de Santa Catarina.

Correspondência / Correspondence Thiago Perez Jorge

E-mail: thipjorge@gmail.com

\section{Resumo}

Comer, nadar, caminhar e brincar tratam da busca de evidências que alargam as relações que envolvem o corpo que come. Este estudo se fez através da prática do piquenique na Ilha de Santa Catarina, entre 1906 a 1918. O local de estudo é o Ginásio Santa Catarina, educandário jesuítico das elites catarinenses. Foi utilizado um amplo acervo documental. Do educandário: diários dos padres, relatórios oficiais do colégio, e fotografias do seu acervo, além de notícias em jornais de época e historiografias sobre o tema envolvendo lazer na cidade. Este é um trabalho historiográfico respaldado em autores da Antropologia, História e Filosofia, cujo objetivo foi promover o diálogo com o campo da Alimentação e Nutrição de modo interdisciplinar. Nesse sentido, entendemos possibilidades para ampliar a construção dos conhecimentos deste campo a partir de aportes teóricometodológicos das Ciências Humanas. Como resultado do estudo, discutimos que práticas alimentares podem tanto fomentar a construção de novas sensibilidades, como no caso do nascimento da prática do piquenique em Florianópolis no início do século $\mathrm{XX}$, quanto potencialmente favorecer a experiência lúdica sob as formas das brincadeiras do corpo que come no ritual que envolve esforço físico. Podemos ainda inferir que há, na brincadeira que envolve corpo e comida, um processo criativo, sensorial e estético. Em suma, o comer participaria, para além dos teores de nutrientes, das relações de saber, de poder e ética nos modos de condução de si mesmo e dos outros.

Palavras-chave: Alimentação. Natação. Caminhada. Jogos. 


\section{Abstract}

Eat, swim, walk and play deal with the search for evidence that broaden relations involving the eating body. This study was carried out by the picnic practice in Santa Catarina Island, between 1906 to 1918. The study site is the Santa Catarina Gym, Jesuit primary school of Santa Catarina elites. A large document collection was used. From primary school: daily priests, school official reports, and photos from their collection, as well as news in newspapers of that time and historiography on the subject involving leisure in the city. This is a historiographical work supported by authors of Anthropology, History and Philosophy, whose aim was to promote dialogue with the field of Food and Nutrition in an interdisciplinary manner. In this sense, we understand possibilities to expand the construction of knowledge of this field from theoretical and methodological contributions of Humanities. As a result of the study, we discussed that dietary practices can either promote the construction of new sensitivities, such as the birth of picnic practice in Florianópolis in the early twentieth century, and potentially favor the playful experience in the forms of the eating body's plays in the ritual that involves physical effort. We can also infer that there is a joke that involves body and food, a creative, sensory and aesthetic process. In short, eating would participate, in addition to nutrient contents, in the relations of knowledge, power and ethics in the ways of managing oneself and others.

Key words: Food. Swimming. Walk. Play.

\section{Aproximações e olhares}

Desde 2001, as "Diretrizes para o Curso de Nutrição" vêm apontando a necessidade de uma formação generalista, humanista e crítica. Seu currículo traz tópicos das Ciências Biológicas e da Saúde, que não contemplam apenas as Ciências Humanas e Sociais (CHS), incluindo Antropologia, Filosofia, Sociologia, ${ }^{1}$ o que implica a própria dinâmica do campo científico da Alimentação e Nutrição.

De acordo com Bourdieu, ${ }^{2}$ o "campo científico" é o espaço simbólico no qual opera o sistema social constituído de relações de força e monopólios, lutas e estratégias, interesses e lucros que condicionam os discursos dos agentes do campo em pesquisa/estudo. No campo, tem-se o exercício da autoridade, com autoridade outorgada a um dado agente. ${ }^{2}$ 
Levando em conta tal dinâmica, aliada a uma perspectiva que busca aprofundar aportes das CHS, temos sobretudo a produção científica de seus dois únicos grupos de pesquisa junto à Área de Avaliação Nutrição da Coordenação de Aperfeiçoamento de Nível Superior (CAPESa). Embora haja relativa contribuição por meio de aportes das CHS, o caminho iniciado ainda é incipiente frente à primazia da lógica biomédica que norteia estudos e pesquisas..$^{3-6}$

De acordo com Nunes, ${ }^{7}$ a racionalidade biomédica(ocidental), suas práticas orientam-se no sentido de: a) combater doenças por meio de tratamento e prevenção; b) agir a partir da definição biológica das doenças; c) otimismo à erradicação vitoriosa sobre as doenças; e d) ensinar um saber biomédico a partir dos pressupostos biológicos de uma Ciência Natural.

Conforme analisou Vasconcelos, há predomínio no âmbito das pesquisas na Pós-Graduação em Nutrição, entre 2003 a 2012, de estudos quantitativos - cerca de 90\%. ${ }^{8}$ Dessa forma, há ainda um árduo percurso para que saberes e práticas a partir das CHS possam se legitimar junto às questões que envolvem o campo da Alimentação e Nutrição.

Dado esse conjunto de argumentos, propomos aqui alguns deslocamentos. Os trabalhos sobre alimentação na área das Ciências Naturais focalizam o óbvio e evidente objeto, o "alimento", e pouco se ocupam em tratar daquele que incorpora o produto culturalmente elaborado e socialmente permitido: o corpo daquele que come.

Nesse sentido, desenvolve-se aqui uma busca de diálogo entre Antropologia e História, para ler relações que envolvem corpo, alimentação, lazer e brincadeira no contexto do desenvolvimento da cidade de Florianópolis. A Ilha de Santa Catarina, este "pedacinho de terra, perdido no mar [...]", é o cenário que envolve relações interdependentes, e não de oposição, no contato entre naturezas ambientais (meio ambiente - flora, fauna, rios, mares e lagos) e urbanidade (a cidade), para construir e desenvolver analítica sobre o objeto "piquenique". 9

No caso, o lócus desta investigação é o Colégio Catarinense, educandário secundário formador das elites catarinenses dirigido por padres alemães que, no decorrer de mais de um século de existência, mudou de nome algumas vezes. Da fundação até 1917, Ginásio Santa Catarina; de 1918 até 1942, Ginásio Catarinense; e desta data até os dias de hoje acompanha a instituição seu nome atual, Colégio Catarinense. ${ }^{\mathrm{c} 10-12}$

a Trata-se do Núcleo de Estudos sobre Cultura e Alimentação (Néctar) da Universidade do Estado do Rio de Janeiro, e do Núcleo de Estudos e Pesquisas Alimentação e Cultura (Nepac) da Universidade Federal da Bahia, onde mais informações podem ser consultadas, respectivamente, em: http://nectar-pesquisa.com.br/site/index. php/nucleo/o-nectar; e http://www.nepac.nut.ufba.br/.

b Incluímos nas Ciências Naturais as Ciências do Alimento e afins.

c Neste ensaio, as fontes selecionadas referem-se ao recorte do então Ginásio Santa Catarina, por isso, será este o nome da instituição adotado. 
Assim, o piquenique é construído ao modo interdisciplinar, orientado "pela fidelidade ao objeto de estudo, e não ao modo de abordar o objeto". ${ }^{13}$ Uma produção cultural localizada na história que envolve o ato de comer, exercícios físicos chamados na época "passeios" ou "marchas", banhos de mar e brincadeiras - em suma, uma historiografia sobre a emergência de novas economias das paixões que afetaram corpos na Ilha de Santa Catarina.

Neste sentido, o ato de comer é mais um elemento, junto ao brincar, banhar e se exercitar, que, em seu conjunto, evidenciam a produção de uma prática que envolve emoção e sensibilidade. Trata-se o piquenique como "exterioridade do acidente" que evidencia uma "proveniência [que] diz respeito ao corpo", isto é, "o corpo: superfície de inscrição dos acontecimentos". ${ }^{14}$

É possível pensar num tipo de prática cultural que dê conta de alargarmos as condições de produção da excitação/emoção deste corpo que come no piquenique? Como o ato alimentar se articula nessa produção? E como tal produção se relaciona com a conjuntura da cidade? Ao tratar de uma história das sensibilidades, problematizações sobre "lazer" e o "processo civilizador" são necessárias.

\section{Aspectos do lazer a partir do processo civilizador}

"Lazer", palavra polissêmica, aqui é lida como passatempo na perspectiva que tratam Elias e Dunning no livro A busca da excitação, ${ }^{\mathrm{d}}$ que, de forma geral, se refere à ideia de que, na sociedade moderna, há diversas formas de lazer que provocam "excitação emocional controlada mas agradável". ${ }^{15}$ Isto leva a "duas funções contraditórias", pois de um lado há "o prazer de desencadear sentimentos humanos", uma "excitação agradável", e de outro há "a conservação de um conjunto de dispositivos de vigilância para manter o agradável descontrole das emoções sob controle" (p. 80). ${ }^{15}$

As ideias desenvolvidas sobre lazer referem-se aos desdobramentos das questões do "processo civilizador", que Elias elabora sobre mudanças das sensibilidades e tipo de controle que se refletem em níveis de pacificação no decurso do tempo em dada sociedade. São tipos de emoções distintas, cotidianas e de passatempo, que devem ser lidas menos como condição catártica de liberação das emoções, e mais inseridas no próprio "processo civilizador", através do dever ser das normas que levam a tipo de adestramento e, assim, evidencia um autocontrole das emoções na personalidade social que se desenvolve. ${ }^{16,17}$

Na teoria do "processo civilizador", Elias elabora um pensamento sintético e interdependente entre ser humano e sociedade, e suas questões não deveriam ser reduzidas a um tipo de teoria evolucionista que tenta prever algum futuro no desenvolvimento da humanidade, espécie

d O livro é um agrupamento dos trabalhos de Norbert Elias e Eric Dunning na década de 1960. Logicamente, há outros autores que desenvolvem perspectivas do "lazer", mas parece oportuno dialogar o ritual do piquenique junto ao "processo civilizador". 
de anunciação de uma raça de super-homens. ${ }^{18}$ Embora esse pensador parta de uma história progressista, isto é, uma historiografia apreendida por narrativas que se sucedem, e se insira na tradição da sociologia teleológica (Marx e Durkheim), que crê que grupos apontam suas condutas para destinos, o processo civilizador, para Elias, culmina, no entendimento de Ghiraldelli Jr., "para situações de maior liberdade". ${ }^{19}$ No entanto, tal processo não trata de uma felicidade, mas uma incorporação no curso de uma vida de padrões de condutas, de comportamentos. ${ }^{20}$

A partir de ampla pesquisa empírica, Elias inter-relaciona os níveis de autocontrole e formação do Estado na diminuição da violência. Hoje se toleram menos ações violentas do que em outras épocas e, banalização do visível, há um relaxamento das normas do dever ser referentes a tipos de comportamento social que vão desde os modos à mesa, passando pelos hábitos corporais de higiene. ${ }^{16,17}$ Portanto, há pressões que atuam sobre indivíduos, de modo a "produzir uma transformação de toda a economia das paixões e afetos rumo a uma regulação mais contínua, estável e uniforme" dos impulsos em todos os setores da vida (p. 202). ${ }^{16}$

Nesse sentido, o que interessa nas pesquisas de longa duração sobre o processo civilizador seria uma leitura retrospectiva da história dos níveis de sensibilidade. Assim, interessam aqui tal autor e seus desdobramentos sobre lazer.

Nos termos do "processo civilizador", que forças atuariam junto aos indivíduos, de modo a transformar novas economias das paixões? Como corpos são afetados através de uma prática cultural localizada no tempo? E ainda, como questões que envolvem alimentação e sociedade podem contribuir no desenvolvimento do "processo" de uma prática que não existia e passou a acontecer? Um olhar às fontes poderá ajudar.

\section{O nascimento do piquenique do Ginásio Santa Catarina}

Era "mais ou menos em meados de janeiro de 1906", quando dois padres receberam por telegrama o chamado para "partir de lá, realmente no meio da noite cheia de neblina, da chácara de São Leopoldo". ${ }^{21}$ esta citação consta nas primeiras linhas do Diário do Padre Prefeito, ${ }^{e}$ escrito a 13 de março de 1906. Era o início de uma história no momento republicano catarinense. Em 15 de março de 1906, o Ginásio Santa Catarina abria suas portas oficialmente. ${ }^{22}$

E, quinta-feira pela manhã, a 15 de março de 1906, ocorreu um banho de mar, "mas o primeiro já ocorrera antes, em 10 de março", e à tarde um passeio, "o primeiro foi em 2 de março, uma sexta-feira". ${ }^{21}$ No dia seguinte, em grifos nossos, novamente apareceu o banho pela manhã, e um escrito se destacou dos demais: “o lugar não poderia ser melhor". ${ }^{21}$

e Os Diários dos Padres Prefeitos apresentam cotidiano do ambiente escolar jesuítico. 
Meses depois, a 15 de maio, o referido Diário aponta que o padre diretor "saiu com alguns alunos a cavalo para encontrar algum lugar adequado para um passeio grande". ${ }^{21}$ Os piqueniques também eram denominados de "passeio grande" nos diários dos padres. ${ }^{21,23}$ Dois dias depois, um jornal da cidade apresentava, nos altos da primeira página, o título "Pic-Nic", e comentava ao final que "nenhum incidente desagradável" ocorrera. ${ }^{24}$

Estas notas esparsas do diário do padre e do jornal apontam primórdios do que serão os convescotes nesta instituição e, que repercutirão pela cidade. Voltemo-nos ao termo em si.

Piquenique, palavra de origem francesa, ${ }^{25}$ é também expressa pelos termos convescote (português) e pic nic (inglês). Na França do século XVII, significava uma prática na qual cada parte levaria sua refeição e, no século XIX, tal atividade de alimentação estendeu-se a lugares como campos e florestas, locais de contato com a natureza e vida selvagem. O quadro de Édouard Manet, Le Déjeuner surl IHerbe, pintado entre 1862 e 1863, ilustra bem tal prática. O que levaria a uma questão: o que o convescote representa em dada sociedade? Retorno ao educandário jesuítico, com seu amplo acervo fotográfico.

As figuras 1, 2 e 3 foram encontradas soltas no interior de um álbum, cujas demais fotografias se referiam à década de 1910. No entanto, elas servem como anteparo para indicar que, até o início das atividades desses padres-professores na cidade, não há quaisquer outros indícios de que o piquenique envolvendo usos da força física, brincadeira, banhos de mar e alimentação em contato com a vida na natureza fossem assim ritualizados em Florianópolis.

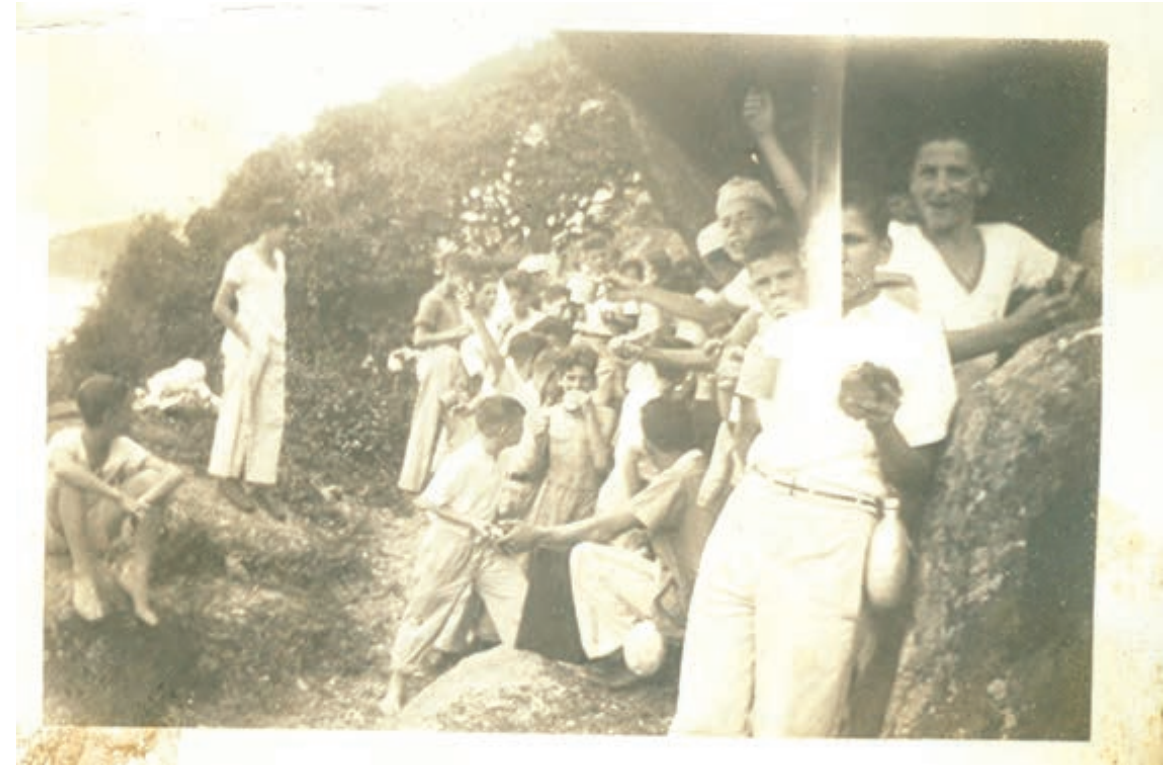

Figura 1. Caminhar, comer e beber no piquenique [191?]

Fonte: acervo fotográfico do Colégio Catarinense 


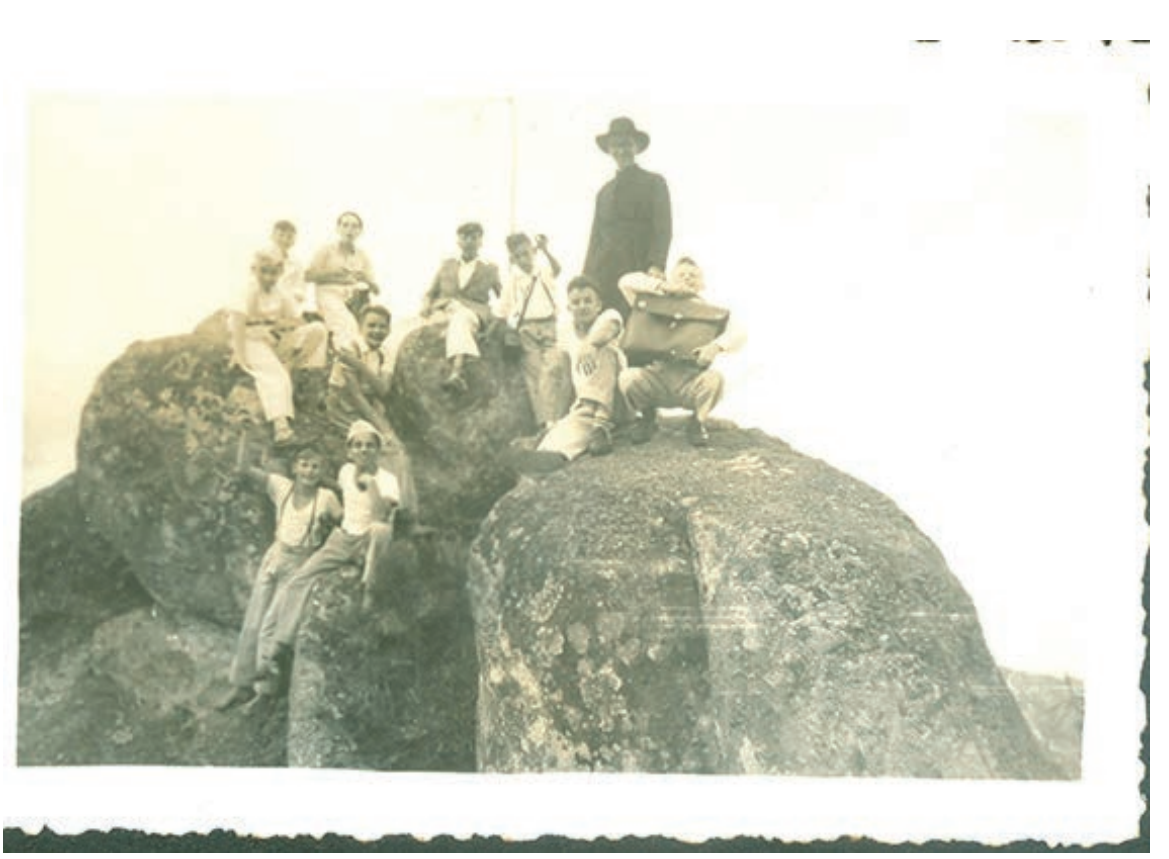

Figura 2. A conquista da natureza no piquenique [191?]

Fonte: acervo fotográfico do Colégio Catarinense

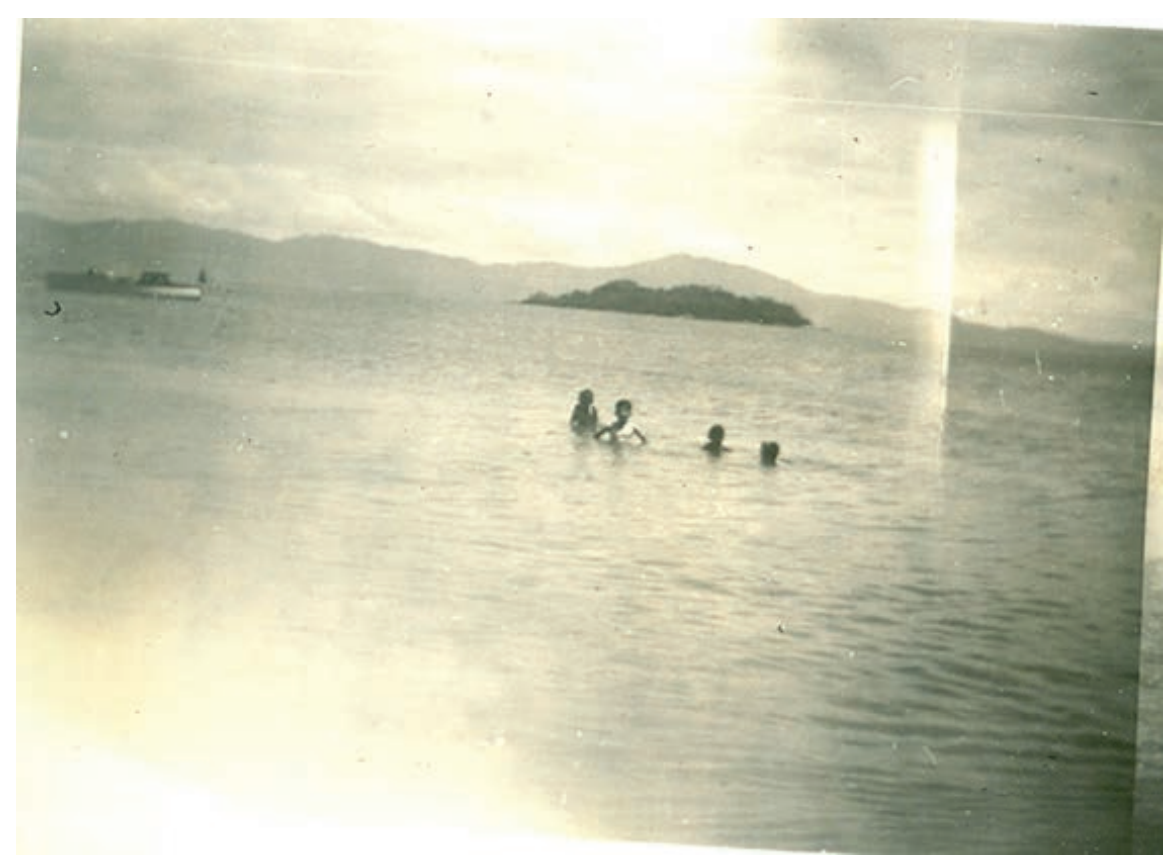

Figura 3. Banho de mar no piquenique [191?]

Fonte: acervo fotográfico do Colégio Catarinense 
Nos relatos dos piqueniques promovidos pelo Ginásio Santa Catarina, há diversos indícios de um ritual a elaborar. Em 1909, a Praia dos Naufragados era qualificada como de lugar "pitoresco e majestoso", onde os alunos puderam conhecer "as ricas e encantadoras belezas da costa do nosso Estado, bem como as inúmeras variedades da nossa Flora e Fauna" ${ }^{26} \mathrm{E}$, dois anos antes, com grifos nossos, o relato no Diário do Padre apresenta que, em 29 de maio, na ocasião da "Santa Missa", grande passeio ao Morro da Cruz, com saída às 8 e chegada às 13 horas, no qual corpos estavam "mortalmente cansados", após uma "comilança de laranjas". ${ }^{23}$

O que há de distinto entre o piquenique, remetendo à origem do termo na França do século XIX, e o "derradeiro piquenique" promovido pelos padres do educandário jesuíta? Usos da força física numa atividade de passatempo, necessidade resultante de uma deliberada e intencional atividade física associada com diversão.

Aqui há um importante fenômeno sobre um ato de brincar, banhar-se e comer, vinculado a um trabalho físico sobre o corpo num momento de lazer junto à natureza da Ilha de Santa Catarina. A prática cultural dos piqueniques deve ser elaborada enquanto princípio utilitário num momento de diversão. E mais, os convescotes precisam ser tratados como práticas que permitem a emergência de novas sensibilidades e emoções, não descoladas de um momento da cidade de Florianópolis. Assim, mergulhado nesta complexidade, talvez sejam os piqueniques fruto de uma "razão prática".

Para Sahlins, a "razão prática” se faz como uma racionalidade inscrita numa forma cultural, e pode sustentar os princípios de utilidade da sociedade "burguesa" através do "esquema simbólico de comestibilidade" relacionado ao esquema que "organiza as relações de produção para precipitar, através da distribuição da renda e demanda, toda uma ordem totêmica, unindo em uma série paralela de diferenças o status das pessoas e o que elas comem". ${ }^{27}$

Sahlins, ao deslocar o pensamento selvagem de Lévi-Strauss para o "pensamento burguês" da hodierna sociedade, questiona os limites do totemismo, que, diferentemente deste antropólogo e filósofo franco-belga, não seria mais um elemento principal do sistema cultural. O que Sahlins sugere é que o totemismo foi substituído na sociedade burguesa "por espécies e variedades de objetos manufaturados, os quais como categorias totêmicas têm o poder de fazer mesmo da demarcação de seus proprietários individuais um procedimento de classificação social” (p. 196-7). ${ }^{27}$

De acordo com Dallabrida, o Ginásio Santa Catarina, única instituição secundária na Primeira República, serviu à "fabricação escolar das elites" catarinenses. ${ }^{11}$ Assim, caberia indagar se o piquenique não seria lugar de distinção social? Qual sua importância no momento republicano da cidade, tempo de consolidação de uma burguesia florianopolitana? 
Num inventário das atividades de piquenique do Ginásio Santa Catarina pela cidade de Florianópolis, apresentados apenas nos Relatórios do Ginásiof entre os anos de 1909 a 1911, as "Crônicas do ano escolar" apresentam que os piqueniques estiveram concentrados entre as regiões central (Morro da Cruz), sul (Armação, Naufragados) e leste (Lagoa da Conceição, Barra da Lagoa) da Ilha de Santa Catarina. Entre os anos de 1912 e 1913, chegam à região norte (Canasvieiras, Santo Antônio e Sambaqui) da capital do Estado, uma "volta à Ilha" cujas regiões passam a integrar itinerário dos "passeios grandes". E, "além do mar", entre 1914 a 1918 ultrapassam-se os limites da Ilha: chega-se ao continente - cidades de São José e Biguaçu / Balneário de São Miguel.

Acompanham os relatos os mais variados elogios (fauna, flora, alimentos, paisagem) de uma prática que fabricada pelos operadores totêmicos (os padres jesuítas) cruzam, associam os esquemas simbólicos de comestibilidade aos esquemas de produção capitalistas. Nesse sentido, as atividades de piquenique fazem parte do mundo de pensamento burguês, donde novos modos de vida são inventados.

Pois, de acordo com Sahlins:

O totemismo moderno não é negado por uma racionalidade de mercado. [...] Ao dar feitio ao produto, o homem não aliena seu trabalho simplesmente, congelado em forma objetiva, mas, pelas modificações físicas que efetua, ele sedimenta um pensamento. O objeto fica como um conceito humano fora de si mesmo, como se fosse homem falando com homem, usando as coisas como meio de comunicação. [...] e porque cada diferença assim desenvolvida pela intervenção com vistas à utilidade necessita ter uma significação e não somente aquelas características, existindo dentro da natureza por suas próprias razões, que se prestem a ser notadas culturamente. O totemismo burguês, em outras palavras, é potencialmente mais elaborado que qualquer variedade selvagem, não que tenha sido liberado de uma base material-natural, mas precisamente porque a natureza foi domesticada (p. 198). ${ }^{27}$

Totemismo burguês que comunica, dá sentidos e significação em forma de utilitarismo. Como na crônica de um dos relatos do passeio grande, na exposição do "espetáculo que davam os pescadores recolhendo-se do alto com suas armações e bonitos lauços", evidenciando uma atividade artesanal como a da pesca. ${ }^{28}$

Sentidos nas fímbrias dos esquemas de produção capitalistas também expressos no passeio "marítimo" ao balneário de São Miguel, "através da baía do Norte" da Ilha de Santa Catarina, o qual entre "canoas de pescadores cheias de camarões, e pomares carregadinhos de frutas",

f Sobre os "Relatórios" do Ginásio, estes eram produzidos ao final de cada ano escolar, reúnem dados estatísticos dos alunos como matrículas, cidade de origem, religião, idade média por curso; e o que interessa, "crônica do ano letivo", espécie de resumo ora mais detalhado ora mais sucinto das diversas ações que tanto equipe docente quanto discente realizou. Aqui estão os piqueniques. 
os alunos admiraram "sinais da indústria do pequeno povo continental" e conheceram logo no ponto do desembarque um "engenho de descascar arroz com suas talhas e estendões do grão e seus maquinismos engrenando numa colossal roda hidráulica"; e mais adiante, "uma serraria trabalhando com a força motriz da mesma água derivada duma represa feita na encosta vizinha. Era uma fábrica de cerveja". ${ }^{29}$

Passeios grandes que vão passando paulatinamente por cada região da Ilha de Santa Catarina, produzindo e significando um "modo de vida definido à sua maneira", uma "reprodução do todo da natureza" que "constitui uma objetificação do todo da cultura" (p. 198). ${ }^{27}$ Assim, as crônicas dos convescotes circulam naquela sociedade processos que destroem a natureza (meio ambiente) e se determinam pelas categorias dos meios e do fim: uma instrumentalidade das técnicas que permitem produzir, armazenar e distribuir alimentos não desaparece depois que seus produtos (peixes, camarões, frutas, arroz, cerveja) são terminados. Pois, de acordo com Arendt, "sobrevivelhe intacto, pronto, por assim dizer, para prestar-se a uma infinita continuação da fabricação" ${ }^{30}$

Logo, é do âmbito da fabricação "a experiência mais fundamental que temos da instrumentalidade", visto que "tudo e todos são julgados aqui em termos de adequação e de utilidade para o produto final desejado". ${ }^{11}$ Fabrica-se um objeto que "fica como um conceito humano fora de si mesmo, como se fosse homem falando com homem, usando as coisas como meio de comunicação" (p. 198). ${ }^{27}$

No totemismo burguês, cada diferença é desenvolvida pelo seu utilitarismo que necessita de significação, utilidade que domestica natureza. No caso, a distinção pela operação totêmica do pensamento burguês reflete-se nos alimentos (peixes, camarões, frutas, arroz, cerveja) que só podem ser apresentados no âmbito do elogio dos passeios grandes porque, antes, já fazem parte como categorias da "diferença”. Por não serem comidas de menor valor simbólico, é que fazem jus à fabricação no/do piquenique.

Ora, seria apenas coincidência os relatos apresentarem aqueles e não outros tipos de alimentos? Engenhos de mandioca não existiam mais em Florianópolis? Por que não apresentá-los nos passeios grandes? Talvez por não significarem distinção social, não interessariam a estes fazedores (padres jesuítas) tal alimento. A mandioca não foi encontrada em nenhum cardápio do cotidiano do educandário. Pelo contrário, o relatório de 1910 apresenta lista de alimentos importados, e dentre eles, a "batata inglesa". ${ }^{2}$

E o arroz, apresentado junto ao seu "engenho de descascar", era consumido depois da saída de outubro de 1919, no almoço que comemorava, dentre outros, o fato de que os alunos internos "perfazem em 90 minutos os 9 km", e assim foram recebidos num "rancho festivo [com] assado, arroz e feijoada, café, pão doce e frutas a fartar". ${ }^{33}$ 
E por que "cerveja” e não outras bebidas? Em 1918, o Diário apresenta que ao final do jogo de futebol entre os times do Internato Vs. Externato, no qual estes "ganharam 2:1", após a contenda foi servido "almoço com cerveja para os jogadores", o que demonstra que esta já fazia parte desse universo simbólico. ${ }^{34}$

E sobre o valor dos frutos do mar, o relato de uma "festa de São João" de 1916 apresenta "bocas de fogo" e "brasas para a sua sardinha, assando peixinhos e até peixes rechonchudos [...] convidando-se uns aos outros para participares da ceiazinha saborosa" (p. 22, grifos nossos)..$^{35}$

Portanto, parece que há relação entre esquema simbólico de comestibilidade e esquema de produção, distribuição e demanda do sistema capitalista, significado nos elogios relatados dos piqueniques do Ginásio. Utilitarismo que concorreria na construção dos mais variados galanteios dessa natureza (ambiental) sendo dominada. Elogios que, na perspectiva de Sahlins, produzem novos modos de vida que une status, grupos e pessoas.

Até aqui, o lugar de diferença do piquenique junto à exuberante natureza da Ilha de Santa Catarina parece justificar ou consentir os avanços de um modo de vida a partir dos discursos de elogios que envolvem utilidades de novos modos de produção capitalista, seja do "espetáculo" da pesca artesanal, seja dos "sinais da indústria". Relação da razão prática do pensamento burguês com a matriz de produção alimentar.

Faltariam indícios da nova economia das paixões no âmbito da personalidade social em desenvolvimento. O modo de vida derivado dos piqueniques aponta outra natureza sendo domesticada: a dos corpos dos alunos.

\section{Em busca do corpo que come, cansa e se diverte}

Situado à beira-mar, em uma das mais pitorescas e saudáveis localidades da bela cidade de Florianópolis, compreendendo vastas áreas para jogos higiênicos e banhos no mar, o Gymnasio Santa Catharina pode garantir aos srs. pais de família tudo quanto se necessita para o bem estar físico de seus filhos [...] Nos intervalos dos estudos haverá recreação, passeios, banhos de mar e exercícios ginásticos (p.54, grifos nossos). ${ }^{32}$

Relatórios $^{g}$ do Ginásio apresentam esta chamada, que se aproveita da localidade da "bela cidade de Florianópolis" e "garante" aos pais o necessário para o "bem estar físico de seus filhos", envolvendo nos "intervalos dos estudos [...] recreação, passeios, banhos de mar e exercícios ginásticos”. Há um utilitarismo da situação beira-mar. 
Acerca do surgimento do banho de mar na cidade de Florianópolis, Ferreira entende que o mesmo ditou novas modas, novos trajes, transformou mentalidades e hábitos, calou preconceitos arraigados e suscitou outros. Há deslocamento de sentimentos e de emoções com a invenção do banho de mar, e uma nova sensibilidade nasce, a do citadino em contato com a natureza. ${ }^{36} \mathrm{O}$ autor encontra em sua pesquisa nos periódicos locais da época, que no início da década de 1920 os banhos de mar foram representados como atividade de "lazer". ${ }^{36}$

Conforme nos indica a figura 3, encontramos fontes que indicam banhos de mar acontecendo neste tipo de piquenique desde 1906, ano da abertura dos portões do educandário jesuítico na cidade. Portanto, há uma prática de educação do corpo, entendendo-a como lazer, sem que, no entanto, tal tema ainda tenha adquirido territorialidade na/pela cidade de Florianópolis. Tal fato leva à necessidade de desdobrar a questão sobre nova economia das paixões perante os convescotes.

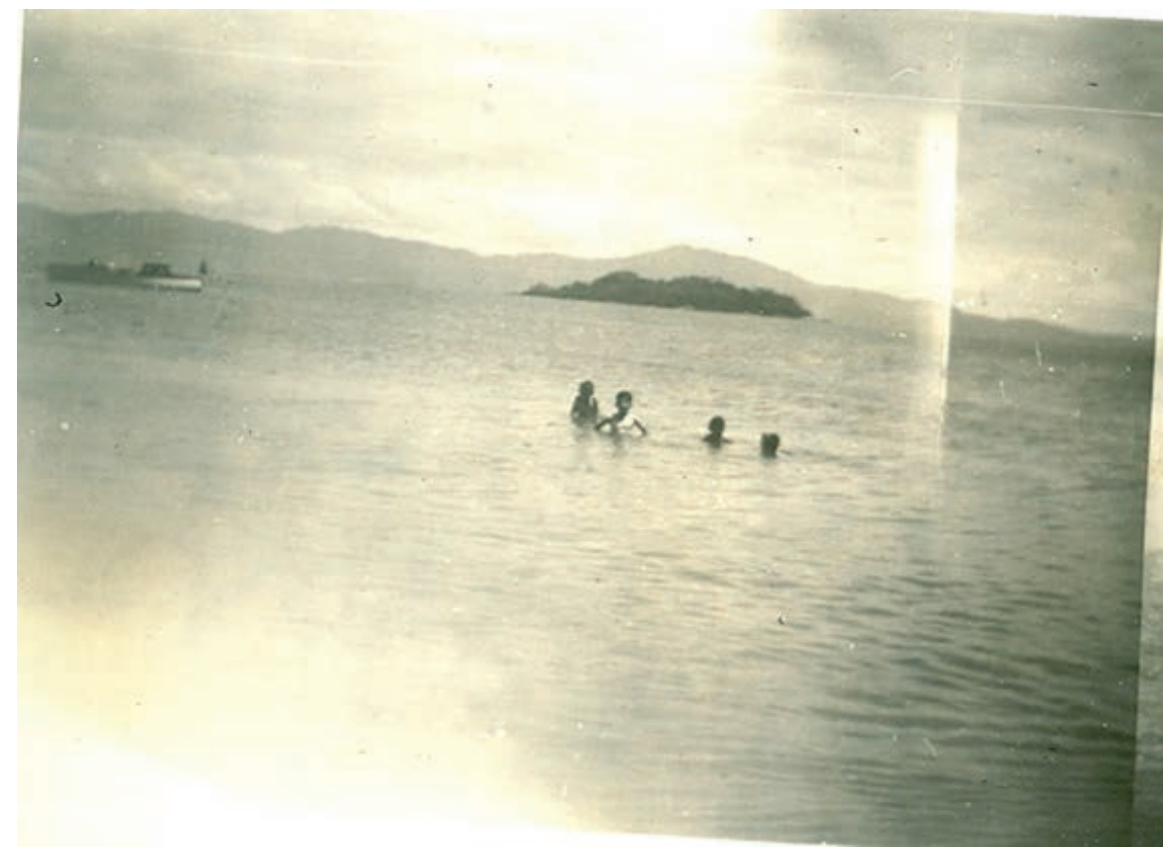

Figura 3 
Neste impasse, Alain Corbin pode ajudar. Esse historiador francês, que pesquisou surgimento do desejo de estar à beira-mar e dos banhos de mar na Europa no livro $O$ território do Vazio: a praia e o imaginário social, apresenta que a prática do banho de mar na Europa teve suas raízes no século XVII e se firmou entre os séculos XVIII e XIX. A partir da segunda metade do século XVIII, despertou no europeu o "desejo coletivo das praias", o qual "as margens do oceano surgirão como alternativa aos males da civilização". ${ }^{37}$

O mar, outrora o quintal, agora ia sendo contornado, como jardins nomeados através dos distintos balneários, e se tornaria expressão da natureza dominada. Obra de uma razão prática do pensamento burguês.

Retornemos às figuras 1 "Comidas e bebidas após caminhada" e 2 "A escalada que revela conquista da natureza não esconde a brincadeira de segurar pasta do padre”. Aqui o diálogo da etnografia com a história produz uma historiografia que não trata apenas do mar, mas de um ritual que também envolve corporeidade e alimentação/comestibilidade/sociabilidade e brincadeira.

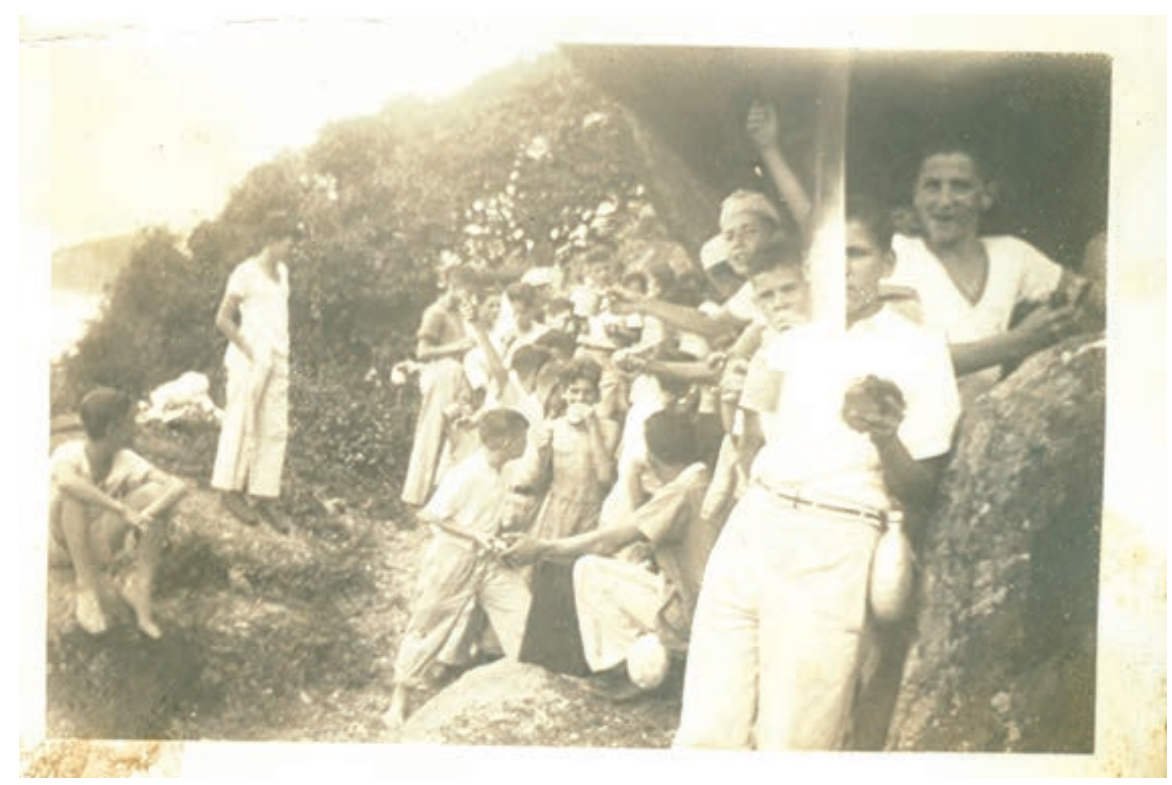

\section{Figura 1}




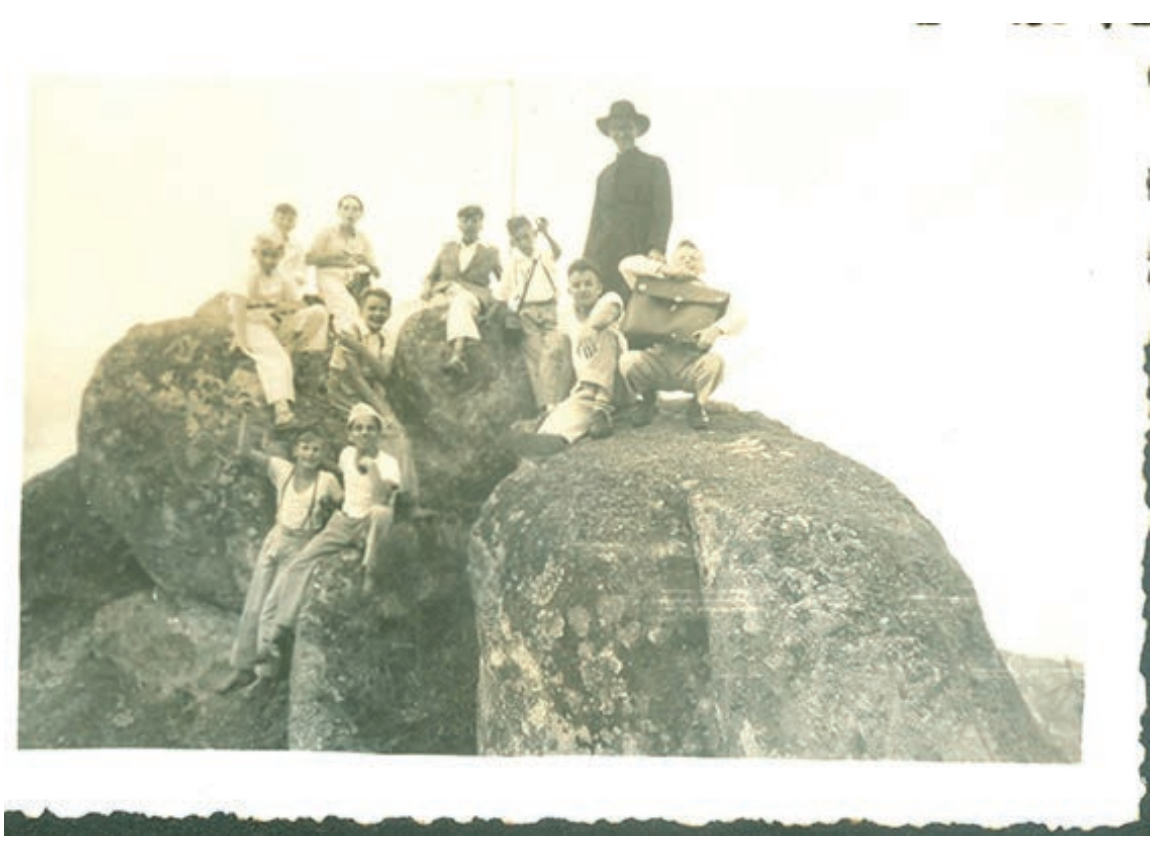

Figura 2

Pululam nas imagens de um passado um conteúdo que pode ser interpretado? Como uma atividade que não existia passaria a acontecer? Que forças seriam estas que na Ilha de Santa Catarina atuariam na expressão de uma natureza sendo dominada? Ou seja: quais elementos contribuem na produção de uma nova sensação: a do corpo que come no piquenique antes, durante e após exercícios físicos? Que condições afetam corpos que brincam e comem?

Fischler pode contribuir nos fios soltos desta busca, ao apresentar que o homem é um onívoro que se alimenta de carne, de vegetais e "[...] de imaginário. A alimentação nos remete à biologia, mas não fica aí, o simbólico e o onírico, os signos, os mitos, as fantasias alimentam-nos, eles também, e concorrem para normatizar a nossa alimentação". ${ }^{38}$ Ora, há em desenvolvimento uma relação de corporeidade até então inédita na cidade. Envolver corpos de alunos em atividades físicas, de mobilidade e de força até então não eram comuns. Nos oitocentos, quando a cidade se chamava Desterro, Cabral destaca que atividades físicas não eram praticadas pela elite.

Como exemplo, têm-se o remo, que "não o era por uma certa mocidade, que não expunha músculos que não tinha, nem fôlego capaz que se levantava às 10 horas do dia, que preferia as práticas do soneto, do namoro [... temendo apanhar vento e expor-se ao sol". ${ }^{39}$ Assim, "quem remava era o pessoal de pegar duro, a turma da pesada, da estiva, [... da marinha mercante ou de guerra, [...] cheirando a uma tragada de cachaça da terra e não a licor de violetas". ${ }^{39}$ 
O primeiro clube deste esporte, datado de 1861 por iniciativas dos oficiais da marinha, convidava sócios para uma regata, não para participarem com sua força no esporte, mas para verem "a gente" do remo fazer força. Assim, para Cabral, "é quase certo que o remo não conquistou os desportistas locais", pois a força que se fazia naquele tipo de embarcação que causava uma "mão cheia de calos" não devia ser muito o gosto "da mocidade fina de Desterro" (p. 216). ${ }^{39}$

Diversão de ver e não fazer no bojo dos hábitos ou costumes que, com a abertura dos portões do educandário jesuítico, deslocariam toda uma relação que envolve corpos, exercícios e naturezas. Há uma ruptura entre aquela elite apontada por Cabral e esta, representada pelos herdeiros-alunos do Ginásio Santa Catarina. ${ }^{\text {h }}$ Como tal processo acontece?

Embora o que se segue é uma hipótese, talvez não seja ingênuo supor que os operadores totêmicos não desconsideram relações alimentares, ou melhor, de comestibilidade e de sociabilidade. Segundo Leach, os critérios de comestibilidade envolvem questões de cultura e de linguagem, e não de natureza, de modo que "nossa" classificação de um alimento é "moralmente justa e marca a nossa superioridade". ${ }^{40}$

Tal perspectiva leva a uma "discriminação cultural" da classificação do "comestível" em três principais categorias:

1. Substâncias comestíveis que são reconhecidas como alimento e consumidas como parte da dieta normal. 2. Substâncias comestíveis que são reconhecidas como alimentos possíveis, mas que são proibidas ou então que se permite comer somente em condições especiais (rituais). Estas são substâncias que são conscientemente interditadas. 3. Substâncias comestíveis que, por cultura e linguagem, não são reconhecidas de modo algum como alimento. Estas substâncias são inconscientemente interditadas (p. 175, grifos do autor). ${ }^{40}$

Aqui, diferentemente do antropólogo britânico, não será dada atenção aos alimentos "inconscientemente interditados", aquelas substâncias comestíveis, mas que não são classificadas como alimento. Busca-se compreender como, no ritual do piquenique do Ginásio Santa Catarina, o que se comia era ao mesmo tempo um alimento presente "como parte da dieta normal", ao passo que era comido em "condições especiais".

Quais as condições para que um alimento normal também seja especial? É possível inferir que na ordem do saber-poder, a classificação do comestível pode participar das transformações rumo a uma nova economia das emoções na Ilha de Santa Catarina? Certamente, a linguagem "faz mais do que nos prover com uma classificação das coisas", pois "molda nosso ambiente e coloca cada indivíduo no centro de um espaço social ordenado de maneira lógica e seguro" (p. 179). ${ }^{40}$

h Dallabrida ${ }^{3}$ demonstra como, a partir de 1906, na instituição jesuítica de ensino secundário se deu a "fabricação escolar da elite" na cidade de Florianópolis. 
De acordo com Leach, "tudo o que é tabu é sagrado, valioso, importante, poderoso, perigoso, intocável, imundo, infando" (p. 180). ${ }^{40}$ Tabu que separa "o eu do mundo e, depois, para dividir o próprio mundo em zonas de distâncias social", que nos termos de Leach correspondem a: casa, fazenda, campo e remoto (p. 192-5). ${ }^{40 \mathrm{i}}$ Assim, motivado pelas considerações deste antropólogo sobre zonas de distância social, talvez seja plausível considerar que o piquenique no início era algo "remoto". Havia necessidade utilitária de construções simbólicas que incidissem na sua materialidade de modo a aproximá-lo das relações de "campo", talvez traduzida pelos termos "pitoresco", "majestoso", "rico", "belo", tantas vezes expressos nos relatórios, que talvez comunicassem nos processos de diferenciação da razão prática espaços mais próximos da "fazenda".

O que interessa aqui é a hipótese de que a relação proporcional do utilitarismo da comestibilidade dos alimentos contribuiria no deslocamento das zonas extremas (casa e remoto, certamente convescotes eram desta última classificação) para as zonas intermediárias (campo e fazenda donde se dão relações de comestibilidade), que, por sua vez, ao garantirem familiaridade (no local desconhecido me alimento do que já conheço), contribuiriam, assim, no desenvolvimento daquela sociabilidade.

Alimentação como recheio das relações sociais e ambientais. O que carregavam nas mãos e canecas que se dirigiam à boca naquela figura 1? Se nossa hipótese pudesse ser verificada - que o esquema simbólico de comestibilidade participa da produção de sociabilidade perante o novo -, então faz sentido sustentar que alimentos do dia a dia do Colégio - frutas, pão, linguiça - também seriam aqueles consumidos nos dias especiais de piquenique.

Em entrevista realizada com egresso do educandário, submetido ao mesmo regime de internato dos estudantes de nosso estudo, mas, logicamente, de outra época (1950), duas falas nos saltaram aos olhos: 1) eram os mesmos alimentos aqueles ofertados no cotidiano e nas saídas do Colégio, visto que "a festa não pode te distanciar do lugar que tu vive"; e 2) sobre a relação entre atividade física e alimentação, nosso informante relata que "era uma coisa muito articulada", visto que "a posição da refeição antecipa o recreio ou alguma atividade". ${ }^{41}$ Estas frases, um tanto soltas, talvez possam ser mais bem amarradas com outros dados de nossa pesquisa.

De volta ao nosso recorte, a 17 de fevereiro consta no Diário (grifos nossos) que "no refeitório dão ao jantar dois pratos de carne" e, em 11 de abril do mesmo ano de 1918, na merenda que precedia o piquenique foram servidos "pão, linguiça e café", este convescote que era uma "marcha forçada dos [alunos] voluntários em volta do Morro da Cruz", que "levaram das 9:30 até 12h", e na volta destes, foram servidos no almoço "pão, linguiça, carne, arroz" (grifos nossos). ${ }^{34}$ Uma prática de exercício físico coroada com almoço.

i Do ponto de vista da comestibilidade, Leach relaciona que se come o que é da "fazenda" (gado, porco) e do "campo" (animais de caça como veado), mas não do "remoto" (animais não comestíveis como elefante, tigre) nem da "casa" (cão, rato). 
No piquenique de 1916, demonstração do "quanto de energia vive e ferve nos nossos jovens, que como brincando venceram distancia de até $40 \mathrm{~km}$ ", quando o "exército disciplinado" na "praia em frente da ilha dos Naufragados [no sul da Ilha]", houve um "curto descanso" no qual fora servido "pão de trigo e de milho com linguiça" que "desapareceu por encanto" e "laranjas de qualidade superior [que] matam-nos a sede" (p. 17-8, grifos nossos). ${ }^{35}$ Nova coroação, agora realizada na volta do piquenique quando foi realizado "um churrasco a gaúcha, preparado por mão hábil, [que] nos convida a festejar condignamente tão vitorioso". ${ }^{35}$

Carnes, pães e frutas, alimentos servidos no cotidiano e no ritual com todo cuidado pelos operadores totêmicos padres-jesuítas, de modo que "não só o café, mas todo o almoço foi servido quentinho" no mesmo piquenique que elogia fabricas de cerveja e de arroz. ${ }^{29}$ Assim, parece haver uma relação entre o "esquema simbólico de comestibilidade" do incorporado e novas formas de sociabilidade (p. 196). ${ }^{27}$ Quer dizer, talvez seja necessário para se distinguir do "outro”, no caso, o ambiente inexplorado (remoto) e, assim desbravar este novo lugar (que será pitoresco, majestoso, rico, belo), relações estruturadas de comestibilidade que facilitam fissuras na abertura para novas configurações através da sociabilidade que o ato alimentar promove: nova artificialização.

Segundo Douglas, na importância de "decifrar uma refeição", devem-se levar em conta as circunstâncias nas quais se come, realiza-se uma refeição - dias de semana, almoço de domingo, festas. ${ }^{42}$ No nosso caso: os dias de piquenique. Dias de passeio grande que, para existirem, i.e., serem inscritos nos corpos, talvez necessitem que operadores totêmicos se aproveitem, no utilitarismo desta razão prática, das relações de intimidade que momentos de alimentação oportunizam. Afinal de contas, "cada refeição está estruturada no evento social que estrutura outros em sua própria imagem" (p. 44). ${ }^{42}$

Se a figura 1 representa uma estrutura de algo parecido com a de "corpos [que] estavam mortalmente cansados" que chegariam à intimidade da "casa" após uma "comilança de laranjas", então o especial do corpo que come neste evento se dá pelo reforço da própria imagem do alimento, que, por ser também consumido na intimidade cotidiana, desloca estranhamento para familiaridade. Afinal de contas, Douglas já apontava que "refeições expressam estreita amizade" (p. 41). ${ }^{42}$ E há mais no ritual de comer do piquenique.

Um utilitarismo que atuaria na transformação das novas economias de paixões, de modo que banhos de mar, caminhadas, em suma, exercícios físicos, parecem estar estreitamente vinculados às relações de comida e de diversão. Corpo que come e brinca. Na figura 2, antes ou depois de comer, mesmo naquela expressão da composição de força física (escalada na pedra) e brincadeira (aluno que pega maleta do padre), ainda assim havia vigilância e controle nesse passatempo. Caso os olhos do padre não autorizassem aquele momento, certamente essa figura não estaria no álbum do colégio. 
Consta no Diário do Padre de 1907 que, a 7 de março, "antes do passeio, a fileira se compôs de forma miserável. Por isso, após o passeio: direto para o estudo. Deixei os malandros somente ir à latrina". ${ }^{23}$ Por isso, neste momento de excitação e de emoção, mantém-se "o agradável descontrole das emoções sob controle" (p. 80). ${ }^{15}$ Tratamos o piquenique como uma das atividades de jogo que Elias e Dunning categorizam. ${ }^{\mathrm{j}}$

Razão prática do qual os padres-professores já entendiam, visto que oriundo do tal passeio grande haveria espécie de alívio do estresse da sociedade de trabalho, pois "um dia por semana, pelo menos, será destinado ao descanso". ${ }^{43}$

O corpo que se diverte, cansa, come e retorna ao ciclo do trabalho escolar, é oportunizado através do objeto piquenique. Orienta-se no utilitarismo de suas práticas, também chamadas de "marchas higiênicas", cuja "respiração de outro ar mais desabafado que o das aulas" faz bem "ao físico dos alunos". ${ }^{44}$

Convescotes que continuamente praticados contribuem para produção desses corpos escolarizados que trabalham. Na modernidade o "trabalho produtivo", isto é, a "glorificação do trabalho" se anseia por uma durabilidade em seus resultados (p. 178). ${ }^{31}$ Afinal de contas "a maior parte da obra no mundo moderno é realizada sob a forma de trabalho" (p. 175)..$^{30}$

Pedagogia jesuítica que se utiliza das características dos passatempos na produção deste corpo fabricado. Ou seja, relações de saber-poder que concorrem a novas economias das paixões por meio da excitação dos convescotes. Atividades de jogos caracterizados pela sociabilidade, mobilidade e mimesis (p. 178-185). ${ }^{15}$

Em cada grande passeio, há aspectos da "sociabilidade", um elemento de prazer que se refere ao sentimento agradável de estar em companhia dos outros sem o peso da obrigação ou do dever desta companhia. ${ }^{15}$

Mas o poder é relacional, logo, "o peso da obrigação" se não existe, é devido ao deslocamento pelos operadores totêmicos, que em seus estratagemas, criam, ora em datas comemorativas da nova república; ora em datas comemorativas da equipe jesuíta, como nos aniversários do Padre Reitor ou festas católicas; motivos para convescotes junto à necessidade catártica deste lazer.

E, assim, inventam-se encontros entre o eu dos sujeitos do piquenique e, outros enquanto lugares e corporeidade até então desconhecidos. Encontros mediados por relações de intimidade e amizade oportunizados pela alimentação. Uma sociabilidade na cidade interdependente de seu meio ambiente (mata nativa, rios, lagos e mares) que transforma hábitos e afeta corpos.

j Como exemplo das atividades de jogos, têm-se a ida ao teatro ou a um concerto, pescar, jogar futebol, dançar ou ver televisão. ${ }^{15}$ Passatempos que tendem a resolver tensões dos ambientes de trabalho através das criações de outras (simuladas) tensões no decorrer de sua dinâmica. Por isso, os piqueniques podem ser lidos como atividades de jogo, resolvem tensões do trabalho escolar na elaboração de novas tensões da atividade em si. 
Pedagogia que vincula alimentação a um trabalho físico sobre o corpo. Tanto no grande passeio ao Morro da Cruz, na ocasião da "Santa Missa", o qual chegaram aqueles corpos "mortalmente cansados", após uma "comilança de laranjas" (grifos nossos) ${ }^{23}$ quanto no passeio de demonstração

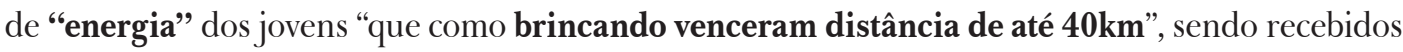
na sua volta, por um "um churrasco a gaúcha, preparado por mão hábil, [que] nos convida a festejar condignamente tão vitorioso" (p.17-8, grifos nossos) ${ }^{35}$

Eis outra forma de excitação: a "mobilidade", decorrente destas atividades físicas que demandam uso da força muscular. ${ }^{15}$ E, conforme as Figuras1, 2, e 3 nos sugerem, relacionam-se atividades físicas (escalada nas pedras, banhos de mar) com esquemas de simbólicos de comestibilidade.

Como exemplo final, este mesmo relato que apresenta atividades físicas também sugere outro modo de excitação que diverte: a imitação. Os jovens demonstraram "energia" brincando ao "vencerem distância de até 40km". Entendemos que os herdeiros das elites catarinenses na vitória do esforço físico celebrada com “churrasco à gaúcho”, vinculando comestibilidade e comensabilidade, imitam, não como repetição do mesmo, mas, produzindo representações do que vem a ser vitorioso.

E Pick, que analisou o educandário até 1970, já demonstrava a importância destes herdeiros para a cidade e o estado catarinense, a partir das práticas de disciplina e lazer/esporte do Ginásio, donde "um verdadeiro exército de quase quarenta mil estudantes que perfilaram pelas salas de aula, pátios e corredores, alcançando muitos, grande destaque local, estadual e nacional” (p.92). ${ }^{10}$

Perceba-se no vínculo comer-atividades físicas: o ato de brincar. Na magia da brincadeira há um "brincar [que] significa sempre libertação" das "crianças [que] não são homens ou mulheres em dimensões reduzidas". ${ }^{45}$

Aqui, interessam as implicações de Benjamin sobre a dimensão existencial (vivencial) dos brinquedos. Ação que deve superar o "equívoco básico que acreditava ser a brincadeira da criança determinada pelo conteúdo imaginário do brinquedo, quando, na verdade, dá-se o contrário". 45 Por isso, mesmo que haja controle e vigilância dos olhares (figura 2), há sempre algo que escapa na experiência do brincar.

A partir do pensamento benjaminiano, apontam-se possibilidades de envolver no objeto piquenique o corpo que come como fonte da ação lúdica na brincadeira. Assim como os "instrumentos de brincar arcaicos", isto é, "bola, arco, roda e penas, pipa - autênticos brinquedos", aliás, "tanto mais autênticos quanto menos o parecem ao adulto" (grifos do autor). ${ }^{46}$ Afinal de contas, é a criança quem determina o brinquedo. Potência do brincar que pode transformar tudo em brinquedo. Magia, pois é o conteúdo imaginário e simbólico na brincadeira da criança quem determina sua atividade lúdica, e não os brinquedos em sua dimensão material.

Como resultado desses convescotes, e sua excitação e emoção decorrentes (das imitações que produzem representações, das sociabilidades e comestibilidades alimentares e atividades físicas), 
temos ressignificação ou criação de novos hábitos. Portanto, a dinâmica cultural não se dá apenas no âmbito da reprodução, mas carrega em si possibilidade de novas produções.

Pois é o jogo, e nada mais, que dá à luz todo hábito. Comer, dormir, lavar-se devem ser inculcados no pequeno irrequieto de maneira lúdica, com o acompanhamento de versinhos. O hábito entra na vida como brincadeira, e nele, mesmo em suas formas mais enrijecidas, sobrevive até o final um restinho da brincadeira. formas petrificadas e irreconhecíveis de nossa primeira felicidade, de nosso primeiro terror, eis o que são os hábitos. [... quando um poeta moderno diz que para cada um existe uma imagem em cuja contemplação o mundo inteiro submerge, para quantas pessoas essa imagem não se levanta de uma velha caixa de brinquedos? ${ }^{27}$

Destarte, infere-se que no valor da brincadeira de corpos com comidas, corpos nos banhos de mar, corpos na atividade física (de força e de mobilidade), há imaginação em ato, potência que determina no brinquedo piquenique um processo criativo e sensorial. Assim, entendemos que tais atividades de lazer contribuíram em ditar novas paixões - corpo que se exercita, brinca, banha-se ao mar ou lagoa, come e bebe. Forças que constroem novo imaginário social. Um piquenique aqui distinto não apenas daquele da França do século XIX, mas produtor de diferença entre aqueles do Ginásio Santa Catarina e os tantos outros da cidade.

Com o nascimento deste modo de vida, surgiram possibilidades para novas simbolizações oriundos deste passatempo, entre signos, mitos e fantasias que Fischler ${ }^{38}$ apresentava, e que também concorreriam para novas normatizações alimentares (o que, com quem, quanto e quando se come no piquenique).

\section{À guisa de conclusão}

Antes de ser o piquenique um divertimento da sociedade de massas, derivando em práticas como trilha, acampamento, produtos da diversão consumidos como quaisquer outros bens de consumo, há a fabricação, no mundo cultural, de relações interdependentes do meio ambiente envolvendo corpos e comidas, brincadeiras, banhos de mar e atividade física, criando novas formas de vida que servem para diferenciar, excluir, privilegiar, próprios do pensamento burguês. E a alimentação, ato de incorporar comida nas novas relações, do corpo que cansa, do ambiente que é nomeado e contornado, precisa ser ampliada para além dos teores de nutrientes.

Deste modo, assumir a complexidade da alimentação na vida em sociedade, passível de ser analisada historicamente, significa ampliar sua participação na forma humana, da qual fazemos parte. E neste trabalho evitamos ao menos duas limitações. 
Inicialmente, não cabe circunscrever algum tipo de hierarquia em nosso objeto. Por isso não faz sentido uma questão para se saber qual dos elementos (comer, nadar, exercitar, brincar) foi o mais importante para o advento do piquenique na Ilha de Santa Catarina. No limite, é da ordem do processo, e não da hierarquia, pois é a complexidade das partes que fundamenta o todo de nosso objeto.

Outra limitação diz respeito aos objetos construídos no mundo da cultura, que respondem às relações que envolvem saber, poder e ética nos modos de condução de si mesmo e dos outros. Apesar de localizarmos a fabricação do piquenique por uma dada elite, à medida que este se torna parte das dinâmicas culturais, escapa às totalizações de algum mito da origem. É que jogos de saber-poder-ética são eles mesmos apropriados no curso do tempo pelos demais agentes sociais (antes excluídos pelos recortes de etnia, classe e gênero). Por isso, piqueniques são plurais, indo além das possibilidades fixadas pela ordem primeiramente construída. Espécie de abertura que alterna, entre a estruturada, obrigatória, e o desvio, ou atalho, por outros caminhos de início um tanto proibidos. Assim, para ampliar as relações que envolvem corpos e comidas, eis a história que contamos, sobre o nascimento do piquenique na Ilha de Santa Catarina.

Por fim, buscamos contribuir com o aprofundamento do diálogo das CHS com o "campo" da Alimentação e Nutrição. Numa frase: partimos do corpo que come brincando a vida, tendo como destino o horizonte deste devir.

\section{Agradecimento}

Agradecimentos ao Colégio Catarinense, pela disponibilidade de acesso aos arquivos e autorização para utilização das fotografias de seu acervo.

\section{Referências}

1. Brasil. Ministério da Educação. Conselho Nacional de Educação. Resolução CNE/CES 5, de 7 de novembro de 2001. Institui diretrizes curriculares nacionais do curso de graduação em nutrição. Diário Oficial da União 9 nov. 2001; Seção 1, p. 39.

2. Bourdieu P. Le champ scientifique. Actes de Ia Recherche en Sciences Sociales 1976; (2/3):88-104.

3. Canesqui AM, Garcia RWD, organizadores. Antropologia e nutrição: um diálogo possível. Rio de Janeiro: Editora Fiocruz; 2005. 306 p.

4. Amparo-Santos L. O corpo, o comer e a comida: um estudo sobre as práticas corporais alimentares a partir da cidade de Salvador, Bahia. Salvador: EDUFBA; 2008. 
5. Freitas MC, Fontes GAV, Oliveira N, organizadores. Escritas e narrativas sobre alimentação e cultura. Salvador: EDUFBA; 2008.

6. Carvalho MCVS. Bricolagem alimentar nos estilos naturais. Rio de Janeiro: Editora UERJ; 2013.

7. Nunes ED. As ciências sociais e saúde na América Latina: tendências e perspectivas. Washington: OPAS; 1985.

8. Vasconcelos FAG. A hegemonia da pesquisa quantitativa nos programas de pós-graduação em Nutrição brasileiros. Rev. Nutrição 2015; 28(1):5-16.

9. Florianópolis. Prefeitura Municipal. Lei 877/68, de 8 de junho de 1968. Oficializa Hino do Município de Florianópolis. Diário Oficial Eletrônico 27 jun. 1968.

10. Pick RJ. O colégio catarinense, um marco na história da educação em Santa Catarina [Dissertação]. [Florianópolis]: UFSC; 1979.

11. Dallabrida N. A fabricação escolar das elites. O Ginásio Catarinense na Primeira República. Florianópolis: Cidade Futura; 2001.

12. Souza RL. Uma história inacabada: cem anos do Colégio Catarinense. São Leopoldo: Ed. Unisinos; 2005.

13. Pedro JM, Scheibe LF. Construção coletiva do Programa de Pós-Graduação Interdisciplinar em Ciências Humanas na UFSC. In: Philippi Jr A, Silva Neto A. Interdisciplinaridade em ciência, tecnologia \& inovação. Barueri, SP: Manole; 2011. p. 426-446.

14. Foucault M. Nietzsche, a genealogia e a história. Foucault M. Microfísica do poder. $25^{\mathrm{a}}$ ed. Rio de Janeiro: Graal; 2012. 65 p.

15. Elias N, Dunning E, organizadores. A busca da excitação. Lisboa: Difel; 1992.

16. Elias N. O processo civilizador. v.1: uma história dos costumes. Rio de Janeiro: Jorge Zahar; 1994.

17. Elias N. O processo civilizador. v.2: formação do estado e civilização. Rio de Janeiro: Jorge Zahar; 1994.

18. Elias N. Introdução à sociologia. 3a ed. Lisboa: Edições 70; 2008. 175 p.

19. Ghiraldelli Jr P. A vez de Norbert Elias. São Paulo: Virtual Books; 2007.3 p.

20. Ghiraldelli Jr P. O corpo filosofia e educação. São Paulo: Ática; 2007. 80 p.

21. Diário do Padre Prefeito Geral do Ginásio Santa Catarina. Tradução de Vera Molenda. Florianópolis: [1906].

22. Ginasio Santa Catarina. Relatório. Florianópolis: Gabinete Tipographico Natividade; 1906. 3 p.

23. Diário do Padre Prefeito Geral do Ginásio Santa Catarina. Tradução de Vera Molenda. Florianópolis: [1907].

24. Órgão do partido republicano catarinense. Jornal O Dia, Florianópolis, 17 maio 1906. Capa.

25. Dicionário. Palavra-chave: dicionário semibilíngue para brasileiros: francês. Trad. Andréa da Silva. São Paulo: Martins Fontes; 2011. 707 p.

26. Ginasio Santa Catarina. Relatório. Florianópolis: 1909. 11 p.

27. Sahlins M. A preferência de comida e o tabu nos animais domésticos americanos. Cultura e Razão Prática. Rio de Janeiro: Zahar; 1979. 
28. Ginásio Santa Catarina. Relatório. Florianópolis: 1912. 9 p.

29. Ginásio Santa Catarina. Relatório. Florianópolis: 1915. 16 p.

30. Arendt H. A condição humana. 11a ed. Rio de Janeiro: Forense Universitária; 2010. 176 p.

31. Arendt H. Trabalho, obra, ação. Cadernos de Ética e Filosofia Política 2005; 7(2):175-201.

32. Ginasio Santa Catarina. Relatório. Florianópolis: 1910. 5 p.

33. Ginasio Santa Catarina. Relatório. Florianópolis: Phenix: 1919. 60 p.

34. Diário do Padre Prefeito Geral do Ginásio Santa Catarina. Florianópolis, [1918].

35. Ginásio Santa Catarina. Relatório. Florianópolis: 1916.

36. Ferreira S L. O banho de mar na ilha de Santa Catarina (1900 - 1970) [dissertação]. [Florianópolis]: Universidade Federal de Santa Catarina; 1994.

37. Corbin A. O território do vazio. A praia e o imaginário ocidental. São Paulo: Companhia das Letras; 1989. $65 \mathrm{p}$.

38. Fischler C, organizador. La nourriture. Pour une anthropologie bioculturelle de l'álimentation. Communications 1979; 31:1-224.

39. Cabral OR. Nossa Senhora do Desterro. v.1: memória. Florianópolis: Lunardelli; 1972. 215 p.

40. Leach E. Aspectos antropológicos da Linguagem: categorias animais e insulto verbal. Matta R. organizador. Edmund Leach. São Paulo: Ática; 1983. Coleção grandes cientistas sociais.

41. Barros M. América. Entrevista concedida a Thiago Perez Jorge. Florianópolis: 12, ago. 2011. Mimeografado.

42. Douglas M. Deciphering a meal. Douglas M. Implicit meanings. London: Routledge; 1999. p. 231-251.

43. Andrade A. Código pedagógico dos jesuítas: ratio studiorum da Companhia de Jesus [1599]: regime escolar e curriculum de estudos. Lisboa: Esfera do Caos Editores; 2009. 290 p

44. Ginásio Santa Catarina. Relatório. Florianópolis: 1913. p.18-19.

45. Benjamin W. Velhos brinquedos. In: Benjamin W. Reflexões sobre a criança, o brinquedo e a educação. $2^{a}$ ed. São Paulo: Ed. 34; 2009. p. 85-86.

46. Benjamin W. História cultural do brinquedo. In: Benjamin W. Reflexões sobre a criança, o brinquedo e a educação. $2^{\text {a }}$ ed. São Paulo: Ed. 34; 2009.

47. Benjamin W. Brinquedos e jogos. Benjamin W. Reflexões sobre a criança, o brinquedo e a educação. $2^{a}$ ed. São Paulo: Ed. 34; 2009. 
